\title{
O uso do Whatsapp como ferramenta de trabalho pelos docentes da UFERSA Angicos e suas consequências na saúde
}

\author{
Aline Carau de Oliveira ${ }^{1}$, Edinadja Mayara de Macêdo ${ }^{2}$, Jacimara Villar \\ Forbeloni $^{3}$, Ramon Williams Siqueira Fonseca ${ }^{4}$ \\ ${ }^{1}$ Licenciatura em Computação e Informática - Universidade Federal Rural do Semi \\ Árido (UFERSA) - Angicos - RN - Brasil \\ ${ }^{2}$ Bacharelado em Sistemas de Informação - Universidade Federal Rural do Semi Árido \\ (UFERSA) - Angicos - RN - Brasil \\ ${ }^{3}$ Departamento de Ciências Humanas - Universidade Federal Rural do Semi Árido \\ (UFERSA) - Angicos - RN - Brasil \\ ${ }^{4}$ Mestrado em Sistemas e Computação - Universidade Federal do Rio Grande do Norte \\ (UFRN) - Natal - RN - Brasil \\ alinecaraudeoliveira@gmail.com, edinadjamacedo98@gmail.com, \\ jacimara@ufersa.edu.br, raamon.williams@gmail.com
}

\begin{abstract}
The technology can facilitate the routines and functions of work activities, decreasing the impact of responsibilities, but at the same time brings dependence, and may cause disturbances and compulsions. Teaching is one of the activities that extrapolates the time of work's dedication and WhatsApp contributes to expand this routine, causing a hyperconnection of the teacher with his professional function, and may cause damage to his/her health. Thus, the present study, which is still underway, aims to verify the use of this communication tool in the teaching space, investigating its effects on the health of teachers of the UFERSA campus of Angicos/RN.
\end{abstract}

Resumo. A tecnologia pode facilitar as rotinas e funções das atividades de trabalho, amenizando o impacto das responsabilidades, mas ao mesmo tempo trazem a dependência, podendo provocar distúrbios e compulsões. A docência é uma das atividades que extrapola o tempo de dedicação ao trabalho e o WhatsApp colabora para ampliar essa rotina, causando uma hiperconexão do professor com sua função profissional, podendo provocar danos a sua saúde. Assim, o presente estudo, ainda em andamento, tem como objetivo verificar o uso dessa ferramenta de comunicação no espaço do ensino, investigando seus efeitos na saúde dos docentes da UFERSA campus de Angicos/RN.

\section{Introdução}

Com o advento da Web 2.0 houve também o surgimento de mídias e redes sociais. Seu uso tem ocasionado mudanças drásticas, reestruturando como os indivíduos se conectam e se relacionam. Essas tecnologias, quando utilizadas no contexto acadêmico, de acordo com Patrício (2010), podem permitir a realização de atividades pedagógicas com 
estratégias inovadoras que têm como principal propósito desenvolver formas interativas e colaborativas de aprendizagem para os estudantes, recorrendo a meios com os quais estão familiarizados.

Dessa forma, essa pesquisa se objetiva a investigar o uso do WhatsApp como ferramenta de comunicação e de auxílio ao ensino. Além disso, os resultados alcançados através dela poderão ser úteis, do ponto de vista institucional, para melhoria do relacionamento dos docentes com a mídia em questão. Também contribuirá para a literatura, pois se trata de um aprofundamento no assunto e os impactos que essa ferramenta pode ter na saúde dos docentes. No âmbito social, esta pesquisa será útil para mostrar a importância de dosar o tempo de dedicação às atividades da docência fora da Universidade.

\section{Mídias sociais}

As mídias sociais têm se apresentado como um dos principais meios de comunicação entre as pessoas que compõem o meio social, dando suporte às redes sociais na internet. É comum confundir mídias com redes sociais, apesar de apresentarem significados distintos, elas participam de espaços e momentos importantes dos vários âmbitos da sociedade em que o acesso à internet é muito ativo [CIRIBELI; PAIVA, 2011].

Pode-se dizer que rede social é um grupo de pessoas com algum grau de relação ou interesse mútuo, mas não se limitam a nenhuma estrutura hierárquica, independente de seu propósito. Já mídia social tem o papel de divulgar o conteúdo ao mesmo tempo que permitem alguma relação com outras pessoas, ou seja, mídia social é o canal que a rede social se utiliza para se comunicar, podendo ter foco em diversas áreas de relacionamento, profissional, pesquisa e entre outras [COSAS, 2011]. O Whatsapp é um exemplo de mídia social, assim como o Facebook Messenger, o Telegram, entre outros.

\subsection{Whatsapp}

O Whatsapp é um aplicativo com o foco direcionado em construir um serviço de mensagens que seja rápido e que funcione em qualquer lugar do mundo. Fundado por Jan Koum e Brian Acton, o Whatsapp juntou-se à empresa Facebook em 2014, porém continua operando como um aplicativo independente. $\mathrm{O}$ aplicativo opera em plataformas móveis, e nos últimos anos se expandiu para desktops usando tecnologia em nuvem/servidor para espelhamento de conversas através dos navegadores de internet ou software instalado no disco rígido dos computadores.

Por estas razões o WhatsApp entrou no seleto hall de serviços que atendem mais de 1 bilhão de pessoas e contam ao menos com $70 \%$ desse público ativo por dia em mais de 180 países, disponibilizando serviços de mensagens e chamadas, segundo o próprio site do aplicativo [WHATSAPP, 2018].

\section{Mídias sociais no trabalho}

Os efeitos das tecnologias da informação (TI) sobre o trabalho e o trabalhador são analisados por Rodrigues (1988) que destaca que a tecnologia da informação modifica a inter-relação do trabalhador com a sua função. $O$ que antes necessitava de um contato 
direto e físico, agora se dá pela intermediação das necessidades. Rodrigues (1988) ainda ressalta que as tecnologias da informação podem ocasionar um estresse elevado se a mudança dessa natureza for drástica.

\section{Mídias sociais na saúde do trabalhador}

Desde sempre, a população de trabalhadores das mais diversas áreas são atingidos por enfermidades "decorrentes dos trabalhos que executam ou executaram e dos ambientes a que estão ou estiveram expostos em função desses trabalhos." [SILVEIRA, 2009, p. 43] essas doenças podem ser desde problemas físicos a distúrbios psicológicos e traumas.

Com o surgimento da tecnologia nas empresas, se tornou possível a ampliação das comunicações através das Tecnologias da Informação e Comunicação (TICs). Elas possibilitam que os trabalhadores estejam sempre em contato e que o empregador contate o empregado mesmo após a jornada de trabalho [FELTEN, 2017]. As mídias sociais como o Whatsapp proporcionam a criação de "grupos de trabalho", fazendo com que o profissional leve as atividades laborais para onde for. Essa realidade full time acaba causando uma hiperconexão do trabalhador, o que acaba violando os direitos fundamentais à privacidade, lazer, repouso e à saúde, pois o profissional permanece conectado com seu contrato de trabalho 24 horas por dia, além de sábados, domingos e feriados [FELTEN, 2017].

\section{Uso do Whatsapp pelos docentes universitários}

\subsection{Histórico da UFERSA}

A UFERSA, inicialmente no ano de 1967 era conhecida como ESAM (Escola Superior de Agricultura) que através da Lei $n^{\circ} 11155$ sancionada pelo antigo presidente Luíz Inácio Lula da Silva transformou a antes ESAM, em Universidade Federal Rural do Semi Árido - UFERSA.

Essa expansão da UFERSA se deve à adesão ao Programa de Apoio a Planos de Reestruturação e Expansão das Universidades Federais - REUNI, uma das ações do Programa de Desenvolvimento da Educação do MEC, instituído pelo Decreto n ${ }^{0}$ 6.096, de 24 de abril de 2007, possibilitando a expansão e interiorização de várias instituições de ensino superior no Brasil [MENEZES; FORBELONI, 2017].

\subsection{Sobre o corpo docente da UFERSA campus Angicos}

Atualmente, o corpo docente da UFERSA Campus Angicos é composto por 98 professores, dos quais 11 são substitutos e 88 são efetivos, destes, 13 estavam afastados para qualificação ou por motivos de saúde no momento da pesquisa.

Do quadro dos professores, 54 são do sexo masculino, 44 são do sexo feminino, 39 possuem mestrado, 53 possuem doutorado, e 6 possuem graduação. Sobre as áreas de atuação, temos professores vinculados aos seguintes departamentos:

- DEPARTAMENTO DE CIÊNCIAS EXATAS E TECNOLOGIA DA INFORMAÇÃO, totalizando 39 professores. 
- DEPARTAMENTO DE ENGENHARIAS, totalizando 44 professores.

- DEPARTAMENTO DE CIÊNCIAS HUMANAS, totalizando 16 professores.

\subsection{Metodologia}

A presente pesquisa é um estudo de caso ainda em andamento sobre os efeitos do uso do Whatssap pelos professores apresentados. Do ponto de vista de seus objetivos, se trata de uma pesquisa exploratória, na qual foi feito inicialmente um levantamento bibliográfico e será usado o questionário como técnica de levantamento de dados [PRODANOV; FREITAS, 2013].

\section{Referências}

CIRIBELI, J. P.; PAIVA, V. H. P. Redes e mídias sociais na internet: realidades e perspectivas de um mundo conectado. Revista Mediação, v. 13, n. 12, 2011.

COSAS, L. O que são redes sociais e mídias sociais? 2011. Disponível em: $<$ http://www.webcortex.com.br/blog/redes-sociais/o-que-sao-redes-sociais-e-midiassociais/>. Acesso em: 10 jun. 2018.

FELTEN, M. C. Os direitos fundamentais e as tecnologias da informação e comunicação: grupos de trabalho do Whatsapp. Revista Thesis Juris. São Paulo, v. 6, n. 1 p. 120-143, 2017. Disponível em: $<$ http://www.revistartj.org.br/ojs/index.php/rtj/article/view/589/pdf $>$. Acesso em: 17 nov. 2018.

MENEZES, Wesliane A.; FORBELONI, Jacimara V. LEVANTAMENTO HISTÓRICO DAS EDIFICAÇÕES DO CAMPUS UFERSA-ANGICOS. Angicos, 2017.

PATRÍCIO, M. R.; GONÇALVES, V. Facebook: rede social educativa?. I Encontro Internacional TIC e Educação, p. 593-598, 2010.

PRODANOV, C. C.; FREITAS, E. C. Metodologia do trabalho científico: Métodos e Técnicas da Pesquisa e do Trabalho Acadêmico. 2. ed., Novo Hamburgo: Freevale, Rio Grande do Sul, 2013.

RODRIGUES, S. B. A Informática na organização e no trabalho. Revista de Administração de Empresas, São Paulo, v.3, n. 29, p.43-50, Jul/ Set, 1988.

SILVEIRA, A. M., Saúde do trabalhador. Belo Horizonte: Nescon/UFMG, Coopmed, $2009 . \quad$ Disponível em: $<$ https://www.nescon.medicina.ufmg.br/biblioteca/imagem/1771.pdf $>$. Acesso em: 12 nov. 2018.

UFERSA. Reitoria: Nossa História. Disponível em: $<$ https://reitoria.ufersa.edu.br/nossa-historia/> Acesso em: 14 de jul. 2018.

UFERSA SIGAA. Departamentos. Disponível em: $<$ https://sigaa.ufersa.edu.br/sigaa/public/home.jsf $>$. Acesso em: 15 nov. 2018. 
WHATSAPP. Sobre o WhatsApp. 2018. Disponível em: $<$ https://www.whatsapp.com/about/>. Acesso em: 20 jun. 2018. 